\title{
"Comulgar con ruedas de molino": el cierre del Fray Gerundio en 1840
}

\author{
Luis GARRIDO MURO \\ Universidad de Cantabria \\ luis.garrido.muro@gmail.com
}

Recibido: 26 de noviembre de 2015

Aceptado: 23 de febrero de 2016

\section{Resumen}

Fundado en abril de 1837 por Modesto Lafuente, el Fray Gerundio fue el principal periódico satírico de su tiempo, así como uno de los más populares y vendidos. Su crítica permanente al poder le valió varias amonestaciones por parte de los distintos gobiernos, la última de las cuales acabó con su cierre en marzo de 1840 por desacato, una acusación que luego se comprobó contraria a la ley. El cierre lo hizo aún más popular y convirtió a Modesto Lafuente en una verdadera celebridad por su defensa de la libertad de imprenta.

Palabras clave: Fray Gerundio; Modesto Lafuente; cierre; 1840

\section{"To swallow anything": the close of Fray Gerundio in 1840}

\begin{abstract}
Founded in april 1837 by Modesto Lafuente, Fray Gerundio was the main satirical newspaper of its time, as well as one of the most popular and sold. As a result of its constant criticism to power, it received many warnings from the different Governments, the last of which ended up with the close of the newspaper despite the fact it was against the law. The closure made it even more popular and Lafuente became a press freedom champion.
\end{abstract}

Keywords: Fray Gerundio; Modesto Lafuente; close; 1840

\section{Referencia normalizada}

Garrido Muro, L. (2016). "Comulgar con ruedas de molino": el cierre del Fray Gerundio en 1840. Historia y Comunicación Social. Vol 21, número 1, páginas 139-153.

Sumario: 1. Introducción. 2. Del convenio de Vergara a la apertura de la legislatura de 1840. 3. El cierre del Fray Gerundio y sus consecuencias. 4. La vuelta del Fray Gerundio. 5. Referencias bibliográficas. 


\section{Introducción}

Las siguientes páginas pretenden iluminar unos meses decisivos de la Regencia de María Cristina (1833-1840) a través de un episodio menor en apariencia, anecdótico casi: el cierre del periódico satírico Fray Gerundio en marzo de 1840. Tratado de refilón en la mayor parte de estudios sobre el periódico a excepción del de Fuertes-Arboix (2014), lo ocurrido puede cobrar una nueva dimensión a la luz de un estudio multidisciplinar como el que aquí se propone, donde se entrelazan la historia del periodismo con la historia política. Esta metodología permitirá saltar de lo particular a lo general y apreciar así la totalidad del cuadro, ya que el cierre del Fray Gerundio, lejos de constituir un hecho aislado y sin ilación con el contexto político, fue la culminación de una deriva iniciada meses atrás con unos propósitos muy bien definidos. La denuncia de lo ocurrido, además de una defensa de la libertad de imprenta, supuso a su vez el banderín de enganche de aquellas fuerzas políticas que se habían ido quedando sin voz en esa misma época por unas razones u otras.

Para lograr este objetivo se ha recurrido al estudio del periódico durante un año, de septiembre de 1839 a septiembre de 1840, así como el de la prensa de más importancia del momento, toda vez que el cierre del Fray Gerundio obligó al resto de cabeceras a tomar partido en uno u otro sentido dada la importancia de lo sucedido. El Diario de Sesiones del Congreso de los Diputados, así como la principal bibliografía política acerca de esos años, completan el resto de fuentes utilizadas.

\section{Del Convenio de Vergara a la apertura de la legislatura de 1840}

El correo que anunciaba el Convenio de Vergara llegó a Madrid alrededor de la una de la tarde del tres de septiembre de 1839, martes, una hora en que la mayoría de la población estaba comiendo o a punto de hacerlo. A pesar de eso, buena parte de ella se dirigió a continuación a la Imprenta Nacional en busca de la Gaceta extraordinaria que confirmara una noticia que había corrido ya de boca en boca gracias al repique general de campanas. En torno a su sede de la calle Carretas hubo abrazos, enhorabuenas, apretones de manos, risas, bromas, júbilo, algaraza y hasta un Gloria in excelsis Deo, cientos de personas que se derramaban ya hasta la Puerta del Sol a la espera de leer la noticia por la que España entera había suspirado desde hacía seis años, pero la extraordinaria no salió hasta última hora de la tarde, y cuando lo hizo resultó ser una cuartilla suelta de 30 de líneas de impresión en la que sólo se incluía el parte de Espartero, no el convenio con Maroto al que hacía referencia. Hubo que esperar a la edición de la tarde del Mensagero del Pueblo para leerlo al fin, un suplemento extraordinario editado a toda prisa a pesar de la prohibición entonces vigente de anunciar periódicos de política por la calle. Ambos papeles fueron devorados a la luz de los faroles después de horas y horas de espera. "Loor a la rapidez tipográfica de la Imprenta Nacional", apuntó un testigo que no pudo regresar a casa hasta la noche'. 
Las cosas de la política fueron en cambio a toda prisa a partir de entonces. Ocho días después de conocerse la noticia, el Gobierno moderado de Pérez de Castro comenzó a presentar a las Cortes distintos proyectos de ley relativos al Consejo de Estado, organización y atribuciones de ayuntamientos, libertad de imprenta, milicia nacional, elecciones y estados de sitio, guerra y prevención, asuntos todos que aún estaban pendientes de legislar desde la aprobación de la Constitución de 1837 y que darían su hechura última al Estado liberal después de seis años de atención casi exclusiva a la guerra. De todos ellos el más importante era el de ayuntamientos, ya que además de sustituir una legislación que se remontaba a febrero de 1823, pretendía sacar a sus adversarios del tablero político mediante la entrega de las operaciones fundamentales del proceso electoral a los alcaldes, convertidos ahora en agentes del Gobierno al ser el ministro de la Gobernación el encargado de su nombramiento de entre los concejales elegidos, otro de los cambios de la ley. Que fueran ellos los responsables de formar el censo, presidir la mesa electoral, realizar el escrutinio y redactar el acta definitiva permitiría al partido en el poder ganar las elecciones casi con toda seguridad y así perpetuarse en el mismo, "porque", como dijeran sus críticos, "el alcalde, siendo dueño de elegir la mesa, lo es también del resultado de las elecciones". Luego disolvió las Cámaras y convocó elecciones para enero de 1840, la segunda disolución en cinco meses, ya que la anterior se había producido en junio del mismo año. La razón esgrimida fue el giro experimentado en la vida política y social del país tras el Convenio de Vergara, "los grandiosos acontecimientos que han cambiado absolutamente el aspecto de las cosas públicas", "circunstancias tan grandes, imprevistas y trascendentales que lo han cambiado todo", pero la disolución obedecía en realidad a su falta de mayoría parlamentaria en el Congreso. El partido del Gobierno, el moderado, sólo contaba con 16 diputados por 90 del progresista. La legislatura de 1839, inaugurada el uno de septiembre, sólo duró dos meses por lo tanto, el tiempo justo para reconocer los fueros vascos y navarro, el compromiso adquirido por Espartero en el Convenio de Vergara. Y por último, se aplicó a los trabajos electorales en cuerpo y alma de la mano del ministro de la Gobernación, Calderón Collantes, el responsable de sustituir a los empleados tibios o contrarios por otros afines, dar las preceptivas instrucciones para favorecer las candidaturas moderadas, y aumentar el censo todo lo posible, la clave de la operación, "porque las listas hacen las elecciones". El número de electores aumentó de esa forma en 80.000 respecto a la convocatoria de seis meses antes, lo que permitió ahogar el voto urbano en beneficio del rural, siempre más proclive al partido moderado, ya por afinidad natural, ya por el peso del notable de turno. ¿El resultado final? Cerca de 200 escaños moderados por apenas 50 progresistas, a lo que había que sumar una victoria parecida en el Senado, un éxito sin precedentes en suma. En apenas cinco meses, los que mediaron desde la apertura de la legislatura de 1839 hasta el escrutinio de las elecciones de 1840, el gobierno de Pérez de Castro consiguió dotarse de un programa claro en forma de proyectos de ley, deshacerse de unas Cortes hostiles, unir al partido moderado a su alrededor y ganar las elecciones por un margen amplísimo, un tocar el cielo con las manos después de haber estado en una posición de lo más apurada en septiembre, cuando la oposición amenazó con "darle un puntapié y echarle por la ventana". Sólo quedaba un último paso: aprobar 
las actas electorales sujetas a reclamación una vez que las Cortes abrieran de nuevo sus puertas, lo que dictaba la ley electoral, un simple trámite en teoría habida cuenta de la amplísima mayoría de que gozaba el partido en ambas Cámaras.

Uno de los periódicos que más y mejor cubrió esta vertiginosa sucesión de acontecimientos fue el que fundara Modesto Lafuente en abril de 1837 en León, el Fray Gerundio, editado en Madrid a partir de julio de 1838 bajo la responsabilidad de Francisco de Sales Fuentes. Subtitulado como Periódico satírico de política y costumbres, giraba en torno a las cuitas, reflexiones y diálogos de un fraile exclaustrado después de la desamortización de Mendizábal, Fray Gerundio de Campazas y Carabanchel de Abajo, y su criado, el lego Pelegrín Tirabeque, una suerte de Don Quijote y Sancho de su época. El propio Lafuente reconoció varias veces que sus modelos eran Juvenal y Cervantes, "[los] dos príncipes de la sátira latina y española", y ese fue siempre el tono del periódico, todavía más acusado durante estos meses en los que parecía que el tiempo se aceleraba a cada paso, "como las natillas", que dijera el goloso de Tirabeque, "que se pasa sin sentir"3.

Como tantos de sus contemporáneos, Fray Gerundio se volvió loco de alegría al saber del fin de la guerra, de ahí que propusiera a Tirabeque bailar "un paspié o una pastorela o solo de rigodón, o minué afandangado, o una figurita de baile inglés, o una jota aragonesa, o una bolera castellana", tras lo cual se acercó a la calle Carretas en busca de la ansiada confirmación oficial. Allí se encontró con "millares de abejas, abejarones y abejarucos, multitud innumerable de zánganos, y no pocas avispas (...) esperando la gaceta extraordinaria que era el panal de miel sobre hojuelas que todos ansiaban devorar". En los días sucesivos asistió a nuevas celebraciones en distintos puntos de la ciudad, pero muy pronto se desengañó acerca de la supuesta época de unidad y reconciliación que se abría entonces a decir de muchos. Como dejara escrito en un poema de días después con su habitual lucidez, "ahora empieza la guerra y el estrago,/ que lo que hubo hasta aquí solo fue amago./ Canten otros la paz con mil amores,/ yo cantaré la guerra y sus horrores./ La cantaré a mi modo,/ que es Fr. Gerundio singular en todo". Esa guerra llegó con los proyectos de ley presentados por el Gobierno a mitad de septiembre, el de organización y atribuciones de ayuntamientos en particular, muy alejado del espíritu conciliador que presidió la elaboración de la Constitución de 1837. A la guerra entre liberales y carlistas le iba a suceder la guerra entre moderados y progresistas en resumidas cuentas. El caballo de batalla de Fray Gerundio fue en todo caso el proyecto de ley de imprenta, un texto de 125 artículos que bautizó como "monstruo de 125 patas", o como dijera en un latín macarrónico herencia de su pasado religioso, "monstrum horredum, centum viginti quince patarum". No era para menos. Si la ley vigente establecía un máximo de 400 reales de contribución directa para ser editor responsable, el proyecto elevaba esa cifra a 1.000, lo que en la práctica suponía reducir los 125 artículos a uno solo que dijera "queda suprimida la libertad de imprenta". Él no pensaba acobardarse de todas formas, así que anunció a mitad de octubre que seguiría "gerundiando al gobierno y a quien sin ser gobierno se desmande, con la esperanza de decirle cuanto en mientes y en razón le venga sin que pueda ninguna de las patas del animalito echarle la garra". Dicho 
y hecho. Dos números después, cargaba contra el presidente del Gobierno, Pérez de Castro, al que tachó de "pobre viejo", "de hálito (...) como el de las culebras de las orillas del Orinoco", "Padre Eterno del ministerio [que] tiene ya las manos muy flojas para guiar las riendas del estado en esta época". La disolución de las Cortes tras solo dos meses de sesiones le confirmó que el Gobierno pensaba llevar la guerra iniciada a mitad de septiembre hasta el final, una decisión de lo más imprudente al tratarse de un momento en que "los ánimos y las pasiones están como cerveza en botella, que apenas se quita el tapón, tal como ahora que se quitó el tapón a la botella de la crisis con el decreto de la disolución, las pasiones se desbordan como el licor fermentado". Con las Cortes cerradas, Fray Gerundio se convirtió a partir de entonces en el principal órgano de la oposición junto con El Eco del Comercio, el otro periódico progresista, los encargados de denunciar el baile de nombramientos decidido por el Gobierno para asegurarse el triunfo en las elecciones, "las vueltas y revueltas y el continuo movimiento y el corre-ve-y-dile en que trae el gobierno a los empleados de uno a otro pueblo y de una a otra provincia". A finales de noviembre calculaba que los afectados entre separados y trasladados eran ya 200, "lo cual debe ser muy conveniente para la salud de ellos mismos, porque como dice Simón de Nantua (...) piedra movediza no cría moho", cifra que se disparó a finales de año. Como denunciara en un villancico publicado el día de Nochebuena: "repantingado en su silla/ como un prior o un abad/ cada ministro a dos manos/ dando destinos está./ A Pedro da una intendencia,/ una jefatura a Juan,/ a Valentín un juzgado,/ a Camilo hace fiscal,/ a Ventura tesorero,/ administrador a Blas,/ secretario a Celestino,// a Pedro-Pablo oficial,//segundo cabo a Marcelo,/ a Remigio general,/ estanquillero a Bernardo,/ saca-mantas a Beltrán"4. Fray Gerundio aprovechaba además la ocasión para felicitar la Navidad a todos sus lectores.

El resultado de las elecciones no le sorprendió lo más mínimo después de tres meses en los que el Gobierno ejerció de "empresario", los jefes políticos de "compradores comisionados de la empresa", y los emisarios del ministerio de la Gobernación de "chalanes": una victoria abrumadora del partido moderado a costa de dar "garrote (...) a la infeliz Da Voluntad Nacional (...), y no es la primera vez que en España sufre este género de suplicio, que no sé cómo tiene cuello para resistir tantos corbatines de hierro como se le van poniendo". Él seguiría "gerundiando" pese a ello, con más fuerza si cabe dadas las circunstancias. Si durante el invierno denunció los manejos del Gobierno, "tres meses consecutivos de aguas y de elecciones, de nieves y de intrigas, de nieblas y coacciones, de vientos y tropelías, de lodos e ilegalidades, de humedades y circulares, de fríos y alocuciones, de votos y resfriados, de toses y cesantías, de catarros y jefes políticos", ahora haría lo propio con los posibles abusos de las Cortes, cuyas sesiones comenzaron el 18 de febrero. La primera piedra de toque sería la discusión de las actas electorales sujetas a reclamación, el debate que abría siempre la legislatura, aunque no se hacía muchas ilusiones dada la abrumadora mayoría parlamentaria del partido moderado y la composición de la comisión parlamentaria, "doce comisionados como doce perros de presa". Lo que debía ser un simple debate parlamentario se convirtió sin embargo en una batalla campal cuando la parte más radical del partido progresista reventó la sesión del día 23 desde la galería de invi- 
tados e intentó asaltar el Congreso al día siguiente, sucesos de los que fue testigo de primera mano como corresponsal parlamentario, "confusión, gritos, tumulto, alaridos, desorden, amenazas, voces de picaros, tunantes, traidores, y otras lindezas, pusieron aquello que era una bendición de Dios". La refriega se saldó con un muerto después de que los lanceros de la Guardia Real cargaran contra los alborotadores para despejar los alrededores de la carrera de San Jerónimo. "A este estado nos ha conducido el exclusivismo y la intolerancia de los partidos. Este es el resultado de haber dado garrote a la Voluntad Nacional. He aquí los efectos de no dejar a los pueblos que nombren sus representantes con entera libertad", se lamentó cuando hubo pasado todo, una de las pocas veces que dejó a un lado su habitual ironía. Las Cortes cerraron sus puertas durante cinco días y el capitán general de la provincia declaró el estado de sitio la misma tarde del 24 de febrero para evitar nuevos desórdenes, decisiones que acató en un principio, porque "yo, Fr. Gerundio de Campazas, no tengo gana de dar otro paseo militar a Carabanchel, me coso la boca a dos cabos, que je ne comprends pas, yo no compro pan en estado de sitio"s.

\section{El cierre del Fray Gerundio y sus consecuencias}

Restaurada la tranquilidad, deshizo su promesa de días antes y anunció su propósito de "seguir gerundiando en el modo y forma de costumbre, o en la que hubiera lugar con arreglo a los estados de sitio, (...) porque Fray Gerundio tiene muy presente aquel precepto de Jesucristo que dice obedite praepositis vestris, etiam discolis: obedeced a vuestras autoridades, aunque manden condenadamente". El estado de sitio fue el objeto de sus burlas a partir de entonces por tratarse de una medida desproporcionada bajo su punto de vista. Unos incidentes como los ocurridos en los días anteriores no justificaban una declaración de esa naturaleza, con el agravante de que ni uno sólo de los alborotadores fue detenido en los días posteriores, de manera que "la cosa quedó como antes (...), sin más diferencia que un hombre menos en el mundo y una albarda más que con pretexto de estas locuras nos pondrá el gobierno". Las críticas le valieron un aviso del Capitán General de Castilla la Nueva con fecha de 28 de febrero en el que se le advertía de posibles "medidas de rigor" en caso de seguir por esa línea, así como la obligación de entregar un ejemplar del periódico dos horas antes de su circulación en la capitanía general y la jefatura política. La publicación se lo tomó con su humor habitual: Tirabeque se despertó mudo ese día, no quiso llamar a un facultativo para tratar su dolencia y se limitó a encogerse de hombros cuando le preguntaron por el origen de su nuevo estado. Comer podía, eso sí, señal de que "no tenía estorbo alguno en la glotis, ni en la epiglotis, ni en la laringe, ni en la traquiarteria", al punto que se frio unos huevos en la cocina y se los zampó en un momento. El que no perdió el habla fue Fray Gerundio, que en el número siguiente volvió a cargar contra el estado de sitio, de lo más permisivo con "una comitiva de enmascarados armados de mazos y espadas, y rodeados de un pueblo inmenso", lo mismo que con la multitud que asistió al entierro de la sardina, "grupos de ocho o diez mil personas". El estado 
de sitio sólo estaba en vigor para amendrentar a periodistas al parecer, o como dijera él mismo en otro de sus poemas, "el pueblo está tranquilo,/ y el sitio dura;/ mala señal es esta para mi pluma./ Clara es la cuenta; si el sitio no es al pueblo,/ será a la imprenta". Harto del asunto, decidió hacer caso omiso de las advertencias y retomó la actividad previa a la declaración del estado de sitio, la discusión de las actas electorales, retomada a su vez por las Cortes en cuanto abrieron otra vez sus puertas, a cuyos diputados recordó que "estamos en tiempo de ayunar: mirad no os traguéis ciertas actas de tomo y lomo, porque vais a perder el ayuno y faltaréis al precepto cuadragesimal". La mayoría del Congreso no encontró sin embargo "espinas ni huesos en las actas, todo es carne mollar", y aprobó en los primeros diez días de marzo 12 de las que estaban sujetas a discusión, algunas tan polémicas como las de Oviedo o Badajoz. "Como piedras de molino son algunas de las actas que (...) traga[n]. El cómo lo hacen, yo no lo sabré decir, pero el hecho es que se las tragan como ruedas de molino, algunas después de una pequeña masticación, otras enteras y como quien se engulle una cucharada de cuajadillas frescas", denunció el diez de marzo, palabras que acompañó de una ilustración en la que aparecían cuatro diputados con la boca abierta hasta el exceso a punto de tragarse varias actas en forma de ruedas de molino (ilustración $\mathrm{n}^{\mathrm{o}}$ 1). "En lo sucesivo en lugar de decir a los niños llorones para hacerles callar por miedo: 'calla que te come el coco', debe decírselos; 'calla que te come la comisión"”, concluía ${ }^{6}$.

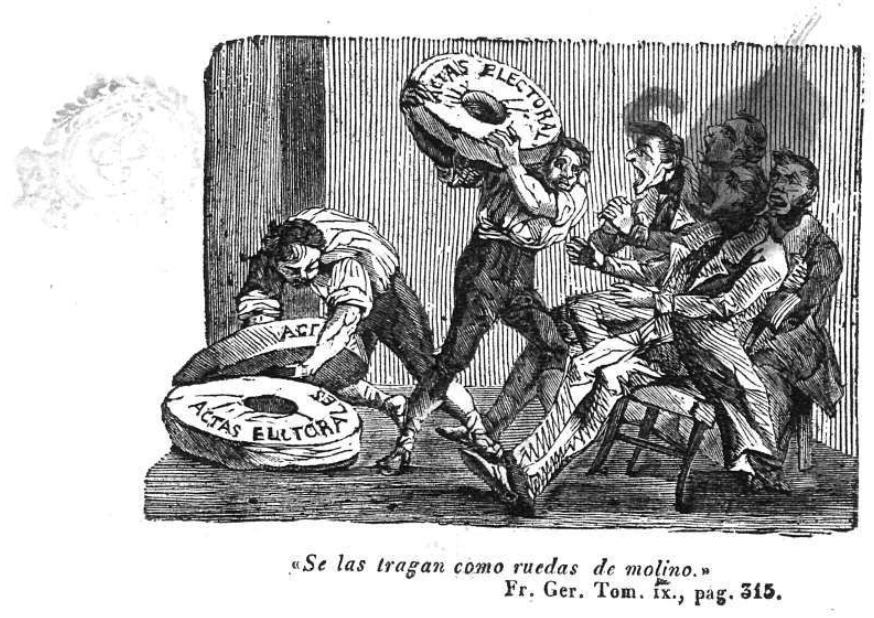

Fuente: Biblioteca Nacional

Las reacciones no se hicieron esperar. Dos días después, el 12 de marzo, el ministerio de Gracia y Justicia publicó una Real Orden en la que ordenaba a los promotores fiscales denunciar y perseguir aquellos periódicos que "ya por la prensa, ya por medio de caricaturas, (...) atent[en] punible y criminalmente contra el respeto y autoridad de 
las Cortes". Las demasías cometidas en las semanas anteriores no debían continuar. Y al día siguiente el editor responsable del Fray Gerundio, Francisco de Sales Fuentes, fue sacado de su cama a las cinco de la mañana y conducido a continuación a la sede de la jefatura política en compañía de su esposa, donde permaneció toda la mañana. Allí se le leyó un oficio del Capitán General de Castilla la Nueva en virtud del cual se suspendía el periódico por desacato a las Cortes en su número del diez de marzo, cuyos ejemplares debían entregarse al inspector de protección y seguridad pública, Carlos Saint Sernin. El dueño de la imprenta, Francisco de Paula Mellado, también fue informado del oficio. Cerrado el periódico, el Gobierno intentó cubrir la decisión con un cierto aire de legalidad habida cuenta de que la única institución que podía dar un paso de esa gravedad era el jurado de acuerdo con el artículo $2^{\circ}$ de la Constitución de 1837 y el título octavo de la ley de imprenta de 12 de noviembre de 1820, aún vigente. Primero elevó el polémico número del diez de marzo junto con su caricatura ante el promotor fiscal militar, que no encontró base legal para denunciarlo, y luego hizo lo propio con el promotor fiscal ordinario, de quien obtuvo la misma respuesta. Ni el texto sobre las actas electorales convertidas en ruedas de molino ni la ilustración que lo acompañaba eran constitutivos del delito de desacato en definitiva ${ }^{7}$. El Gobierno no dio marcha atrás pese a ello y anunció que el periódico estaría cerrado hasta nueva orden.

El primero en reaccionar fue El Eco del Comercio, que al día siguiente del cierre del Fray Gerundio informó de lo sucedido y lamentó en una tipografía más grande de lo habitual que "si ha llegado ya el caso de volvernos al régimen absoluto, como parecen indicar los hechos, dígase claramente de una vez. Si no es así, y hemos de vivir bajo el sistema establecido por la Constitución, respétesela y obedézcanla todos, gobernantes y gobernados". La información estaba presidida por el artículo $2^{\circ}$ de la Constitución, el que establecía el derecho a imprimir de todos los españoles y la calificación de los delitos cometidos durante su ejercicio por el jurado en exclusiva. El periódico siguió denunciando el cierre durante los días siguientes, "el gravísimo e indisculpable atentado cometido con Fr. Gerundio", "una brecha en el sistema constitucional, que si pronto no se cierra, podrá causar la ruina progresiva y rápida de las instituciones", de tal manera que Modesto Lafuente no pudo menos que agradecerle el gesto en una carta publicada el 21 de marzo, "testimonio público de mi agradecimiento, al propio tiempo que de mi sincero reconocimiento a las honrosas calificaciones con que hablando de mi persona se han servido vds. distinguirme". Llevaba escondido desde el día antes de la suspensión del Fray Gerundio, temeroso incluso por su vida después de recibir un aviso en ese sentido, pero no podía dejar pasar de largo lo hecho por El Eco del Comercio en esos días, "el interés, calor y valentía con que (...) han levantado su voz (...) en varios números de su apreciable periódico contra la escandalosa tropelía que con el mío se ha cometido". La otra cara de la moneda fue El Correo Nacional, el periódico conservador de más tirada de Madrid, para quien el cierre del Fray Gerundio estaba disculpado al tratarse de una medida tomada en el marco de la declaración del estado de sitio. "Es necesario respetar sus providencias interinas si con ellas el orden se asegura", justificó en su número del 15 de marzo. Aún más, en los días sucesivos publicó varios artículos en 
contra de los excesos de la imprenta de las semanas anteriores, "las demasías", "el ridículo", "la diatriba", "la befa", recursos utilizados para socavar las instituciones que tanta sangre había costado levantar, no para apuntalarlas. La imprenta debía ser por el contrario el lugar donde presentar, contrastar y discutir las ideas, nunca el de los dicterios y personalidades, porque entre hacer la oposición y combatir las instituciones había una distancia fundamental que nadie debería recorrer. "Pónganse en ridículo las Cortes, y combátase el prestigio de la Corona; ¿qué queda en la sociedad? El poder de la fuerza, las tropelías sangrientas de la muchedumbre, o las venganzas del despotismo. He aquí (...) lo que nosotros queremos evitar pidiendo que la ley con todo su vigor refrene las demasías", concluía el periódico en un artículo firmado por Joaquín Francisco Pacheco, diputado de la mayoría moderada y futuro presidente de Gobierno. El Castellano y El Mensagero, cabeceras de mucha menos tirada pero de ideas parecidas, también se sumaron a la línea editorial de El Correo Nacional ${ }^{8}$.

El cierre del Fray Gerundio saltó luego a las Cortes. Iniciado el debate de contestación al discurso de la Corona, aquel en el que se discutía y votaba el programa presentado por el Gobierno al comienzo de la legislatura, uno de los líderes de la oposición, Cortina, aprovechó la ocasión para denunciar todo lo ocurrido desde el diez de marzo a pesar de que en el texto sólo se hacía referencia a la declaración del estado de sitio, no a la suspensión como tal. Un atropello como ese era un argumento demasiado bueno como para dejar pasarlo de largo, así que Cortina se recreó en la narración de los hechos por más que no quedara nadie ya a esas alturas que no los conociera en toda su extensión: el Capitán General de Madrid había suprimido un periódico sin tener autoridad para ello, ya que sólo el jurado podía tomar una decisión de esa magnitud, tras lo cual se había hecho además con los ejemplares que aún estaban en sus oficinas. "¿Con qué autoridad (...) se entromete a calificar un impreso, y con qué autoridad, haciendo tal o cual calificación de él, suspende un periódico y ocupa los números del mismo?", se preguntó. Aún peor, los periódicos que cargaban contra la oposición acusándola de promover motines y escándalos no merecieron siquiera una amonestación, mientras que el Fray Gerundio fue suspendido a las primeras de cambio, señal de que el Capitán General de Madrid actuó como ariete del Gobierno y no a título particular. Era a él a quien había que señalar por lo tanto, el responsable último de que "la ley esté infringida, la Constitución violada y de que lo que se ha hecho sea no solo ilegal, sino injusto, porque se ha tomado por pretexto una cosa que no podía ser bastante para suprimir un periódico". La réplica corrió a cargo del ministro de Gracia y Justicia, Arrazola, el encargado de fijar la posición del Gobierno después casi dos semanas de silencio. Su argumento consistió en eximir de culpa al periódico, sujeto al artículo $2^{\circ}$ de la Constitución como todos los demás, y cargar contra la caricatura que lo acompañaba, la verdadera causa de su cierre, legal de principio a fin por lo demás. “¿El grabado es la prensa? ¿La pintura lo es acaso?”, se preguntó en voz alta durante su discurso. No a su juicio, "porque una cosa es la prensa, otra el grabado, y otra la pintura", de manera que prohibir una caricatura no suponía atentado alguno contra la ley de imprenta o la Constitución. Las causas para su suspensión estaban además más que justificadas al tratarse de un insulto a la representación nacional, "unos mamarrachos en que se representaba a los Diputados 
de la Nación en una actitud ridícula, con unas ruedas de molino por delante en que se figuraban las actas electorales en ademán de tragárselas". Y si al final se cerró también el Fray Gerundio se debió a que periódico y caricatura formaban parte del mismo ejemplar y no era posible separar uno de otra, una suerte de daño colateral. "Era inseparable una cosa de otra", se lamentó Arrazola. La oposición no pudo menos que reconocer la astucia del ministro, "pues sabe capear bien, sabe huir, sabe evitar las dificultades; y cuando los argumentos son fuertes, sabe flanquearlos", "todo el mundo reconoce en él esta habilidad", pero deshizo sus argumentos con la legislación en la mano. Conforme al artículo $5^{\circ}$ de la ley adicional de imprenta de 12 de febrero de 1822, "los dibujos, pinturas o grabados están sujetos a las mismas reglas, calificaciones y penas que se prescriben para los impresos en la ley de 22 de octubre de 1820 y en la actual", o como dijera Calatrava durante el debate parlamentario, "con arreglo a la ley las caricaturas están sujetas al mismo procedimiento que los impresos". No cabía por tanto otro trámite para su denuncia que los establecidos en las distintas leyes de imprenta y la Constitución, lo contrario de lo que sostenía Arrazola. Las cosas estaban más que claras ya a esas alturas: el Gobierno había incurrido en "una infracción abierta, evidente, de la Constitución y de las leyes del Reino", "[y] el día que se atente impunemente a la libertad de imprenta creeré yo que estamos en vísperas de que se atente a todas, y de que concluya la de España sin un esfuerzo extraordinario". Llegados a ese punto, la mayoría del Congreso sacó su artillería y cargó sin medida contra el Fray Gerundio para justificar su cierre, sin entrar ya en disquisiciones legales. El periódico era responsable de "dirigir artículos infames e injuriosos contra la Majestad del Trono, contra la Regencia de nuestra augusta gobernadora, contra la Constitución del Estado, contra (...) los Cuerpos Colegisladores", había dado lugar a "que la tranquilidad pública se altere, se perturbe el orden", y tenía en su haber "el agravio, el menosprecio, el vilipendio que recaía sobre la Representación nacional". ¿La solución? "Que inmediatamente se le arranque la pluma de la mano, y se suspenda", "una necesidad inminente", "un cargo que [no] se puede hacer a la autoridad". "El Gobierno hubiera faltado a su deber no obrando como lo hizo", concluyó el ministro de la Gobernación, Calderón Collantes9.

\section{La vuelta del Fray Gerundio}

El Fray Gerundio volvió a salir a la calle a la conclusión del estado de sitio, el 20 de marzo. Fiel a sí mismo, utilizó su humor de siempre para hacer la relación cronológica de todo lo sucedido desde su cierre, diez días de lo más intenso. Fray Gerundio, o Modesto Lafuente, que tanto daba, salió de Madrid el 12 de marzo tras ser avisado por el "ángel de los gerundios" de que el Gobierno quería desterrarle al peñón de la Gomera, "a tomar los aires de la costa que suelen ser muy provechosos para la salud". En el escondite donde puso a salvo "mi respetabilísima gerundiana humanidad, para que cuando el rayo se desgajara de la nube cayera en lugar desierto y despoblado", tuvo noticia del cierre de su periódico y de las ominosas circunstan- 
cias en que fue trasladado su editor responsable a la jefatura política de Madrid, así como del secuestro de los ejemplares de la edición del día diez, "los insignes trofeos de aquella memorable, arriesgada y heroica batalla, que llamo yo por la analogía del consonante la batalla de Saint Sernin". Carlos Saint Sernin era el inspector de protección y seguridad pública de la ciudad. Condenado por tanto a no poder publicar, Fray Gerundio, convertido ya en "Fray Gerundio el de las Ruedas de Molino", decidió aprovechar su exilio voluntario en buscar el desacato hecho por su periódico a la representación nacional, la causa esgrimida para su cierre. No lo había en decir que la comisión parlamentaria y la mayoría del Congreso se tragaban las actas electorales como si fueran ruedas de molino, porque ni una sola fue rechazada a pesar de que existían reclamaciones de bastante gravedad, algunas reconocidas por la propia comisión. El promotor fiscal militar primero y los civiles después, "hombre[s] de más médula cerebral que los ministros", no pudieron menos que darle la razón cuando analizaron la causa. Tampoco lo había por criticar a la mayoría del Congreso, ya que varios periódicos hacían lo mismo con la minoría y ninguno de ellos había corrido la suerte del Fray Gerundio, y tan representación nacional era una como otra. Así que el único desacato que encontró fue el cometido por el Capitán General de Madrid y su decisión de suspender un periódico sin mediar la denuncia correspondiente, al que había que añadir el del Gobierno por mandar o consentir esa tropelía en contra de lo establecido en la Constitución, texto que debía cumplir y hacer cumplir en su condición de poder del Estado. "O soy más lego que todo el verbo de la tercera conjugación de la gramática latina, o han cometido un DESACATO a la ley tamaño como una rueda de molino, ECCE DESACATUM TANQUAM MOLA MOLENDINI", concluía. Levantado el estado de sitio, "22 días, 23 horas y 25 minutos, segundo más o menos", cuyo único resultado fue suspender un periódico "en octavo marquilla", Fray Gerundio abandonó su refugio y regresó al fin a casa. Allí se encontró con Tirabeque recuperado de su antigua mudez, si bien sentía la lengua "algo torpe (...) ahora al principio por la falta de uso, y aún me temí que como está siempre metida entre humedad se me hubiera enmohecido algo; pero no ha hecho sino crecerme mucho". Aún más, tantas eran las ganas que tenía de volver a hablar después de esas semanas de silencio, que le habían salido lenguas hasta en los codos, "porque por los codos pienso hablar ahora", una mutación que se le antojaba insuficiente así y todo. De haber podido elegir le hubiera gustado que los dedos de sus manos fuesen lenguas, y cada uña una lengüetilla, "y que se pudieran mover todas a un tiempo como las llaves de una flauta o de un clarín". Todo volvía a la normalidad en definitiva tras "esta gloriosa aventura", y para demostrarlo el periódico incluyó una nueva caricatura en la que aparecía el bueno de Tirabeque mostrando una enorme lengua a varios diputados, el resultado de llevar tanto tiempo sin usarla, aunque más bien parecía un gesto de burla que otra cosa (ilustración $n^{\circ} 2$ ). Y es que ya había advertido Fray Gerundio a su salida de su escondite que "seguiré en mi tarea periodística, ni más ni menos que hasta aqui" ${ }^{\prime 10}$. 


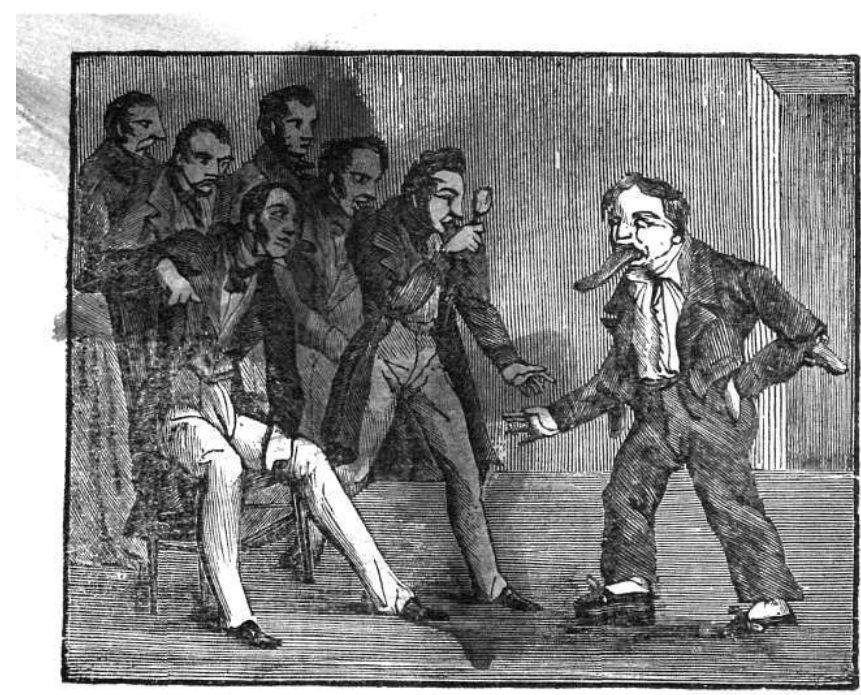

"ithirad como me ha crecido de: de que no la uso!"

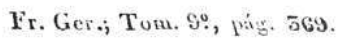

Fuente: Biblioteca Nacional

El cierre del Fray Gerundio no impidió sin embargo que su contenido se conociera en todo el país debido a la torpeza del Capitán General a la hora de emitir la orden. El ejemplar con la famosa caricatura se publicó el diez de marzo, martes, y esa misma noche salió ya con el correo para las provincias de Levante, Andalucía y Extremadura. Al día siguiente lo hizo en dirección a las dos Castillas, Galicia y Asturias. Y dos días después, jueves, se distribuyó en toda la línea de Madrid a Francia, de tal manera que para cuando el Capitán General decidió su cierre, viernes 13, sólo quedaban 40 ejemplares en sus oficinas. El Fray Gerundio se vendía entonces en todas las capitales de provincia, así como en localidades de menor entidad como Astorga, Ferrol, Mequinenza, Mondoñedo, Ronda o las posesiones españolas en las Antillas, lo que hacía de él el periódico de mayor tirada del país con más de 6.000 ejemplares. Su cierre, además de contrario a la Constitución, fue inútil por lo tanto, porque el día de autos ya estaba toda la edición distribuida, "andaban rodando ya las ruedas y las capilladas en muchos miles de ruedas y muchos miles de capilladas en todas direcciones y por todos los caminos", tal y como reconociera el propio Modesto Lafuente. Saber que había sido cerrado y su tirada secuestrada provocó además que el interés por el número en cuestión se multiplicara, lo habitual en estos casos, así que no dejó de ganar suscriptores en las semanas siguientes caso de Pascual Madoz, que reconoció en el Congreso que "no lo leo nunca, y ahora en recompensa de esta persecución del Gobierno he creído de mi deber suscribirme". "[El] periódico se solicita en Cádiz con ansia desde que le suspendió en Madrid un Capitán General imprudente y arbitrario", confirmaba un particular a mitad de abril. El cierre durante diez días fue 
en definitiva la mejor campaña publicitaria posible para hacer del periódico el más popular del momento, la puerta de entrada para un aluvión de nuevos lectores, porque como reconociera su responsable, "con esto acudirán suscriptores a Fr. Gerundio como granos acuden a molino harinero. Y Fray Gerundio, a quien se quiso traer rodando por esos caminos, les dará ruedas, y ruedas sin fin". A partir de entonces hubo viajeros que preguntaban por Fray Gerundio y el lego Tirabeque al llegar a Madrid en la convicción que eran personas de carne y hueso. Y un año después, Modesto Lafuente fue recibido con repique de campanas y serenatas durante un viaje por Andalucía ${ }^{11}$. Se había convertido en un verdadero escritor público.

Meses después, los excesos del Gobierno cayeron sobre uno de los periódicos que más aplaudió el cierre del Fray Gerundio en su día, El Correo Nacional. Cesado el Gobierno de Pérez de Castro tras la revolución de septiembre de 1840, la Junta de Madrid decretó el destierro de tres de sus redactores, Manuel Pérez Hernández, José Bravo Murillo y Joaquín Francisco Pacheco, los cuales debían partir de inmediato a León y Zaragoza. El Fray Gerundio fue entonces el único medio en salir en su defensa, al extremo de acusar a la Junta "de querer coartar la libertad de escribir", para pedirla a continuación que reconsiderase su decisión "en el nombre de Dios y del artículo $2^{\circ}$ de aquella que queremos conservar ilesa y pura". Eso sí, aprovechó la ocasión para recordarle a Pacheco aquellos días en que "tronabas y relampagueabas, imprecabas y deprecabas, concitabas y excitabas, pedías, solicitabas y demandabas medidas rigurosas, ásperas, duras, fuertes, escabrosas y severas", aquellos artículos de El Correo Nacional contrarios "a la caridad, a la humanidad, a la piedad y a la mutua confraternidad que en la cofradía periodística era debida, usada, precisa y acostumbrada". Él, Fray Gerundio, Fray Gerundio de las Ruedas de Molino, sí se acordaba, y por eso ahora "mi paternidad (...) te compadece como no me compadeciste, te defendería como no me defendiste (...), o ya que defenderte no pueda, siento al menos tu mal como tú el mío no sentiste, y de ningún modo trataría de agravarle como tú trataste". La libertad de imprenta, el famoso artículo $2^{\circ}$ de la Constitución, debía defenderse siempre en resumidas cuentas. Y eso valía tanto para cuando el Gobierno era de tus mismos colores políticos como lo contrario ${ }^{12}$.

\section{Referencias bibliográficas}

ÁLVAREZ BERANGO, L. (2000): "Encuentros en la tercera vía. El problema de la conciliación liberal en el proceso político de 1837 a 1844", en Revista de las Cortes Generales, $\mathrm{n}^{\mathrm{0}}$ 51, pp. 7-42.

FUERTES-ARBOIX, M. (2014). La sátira política en Fray Gerundio (1837-1842) de Modesto Lafuente. Alicante. Publicaciones de la Universidad de Alicante.

GÓMEZ APARICIO, P. (1967). Historia del periodismo español. Madrid. Editora Nacional. 
LAFUENTE, M. (2002): Historia general de España desde los tiempos más remotos hasta nuestros días: discurso preliminar. Edición de Juan-Sisinio Pérez Garzón. Pamplona. Urgoiti.

MARCUELLO BENEDICTO, J. I. (1986). La práctica parlamentaria en el reinado de Isabel II. Prólogo de Miguel Artola Gallego. Madrid. Congreso de los Diputados.

PASTOR DÍAZ, N. y CÁRDENAS, F. (1845): "Joaquín Francisco Pachecho", en Galería de españoles célebres contemporáneos o biografias y retratos de todos los personajes distinguidos de nuestros días en las ciencias, en la política, en las armas, en las letras y en las artes. Madrid. Imprenta y librerías de D. Ignacio Boix, tomo VI, pp.

PIRALA, A. (1984): Historia de la guerra civil y de los partidos liberal y carlista. Madrid. Turner/Historia 16, tomo VI.

TOMÁS VILLARROYA, J. (1990): "Las listas electorales en 1840", en Estudios históricos. Homenaje a los profesores Jover Zamora y Palacio Atard. Madrid. Editorial Complutense, pp. 85-100.

VARELA SUANZES-CARPEGNA, J. (1984): "La Constitución española de 1837: una Constitución transaccional", en Revista de Derecho Político, n 20, pp. 95-106.

\section{Notas}

1 Fray Gerundio, 6 de septiembre de 1839, pp. 311-312 y 314. Gaceta extraordinaria de Madrid, 3 de septiembre de 1839. El Mensagero del Pueblo, 3 de septiembre de 1839.

2 DSS. Legislatura de 1839 , apéndice $1^{\circ}$ al $\mathrm{n}^{\circ} 5,11$ de septiembre de 1839, pp. 25-26. DSC. Legislatura de 1839 , apéndice $2^{\circ}, 3^{\circ}, 4^{\circ}$ y $5^{\circ}$ al no 14,14 de septiembre de 1839 , pp. 175-213. DSC. Legislatura de 1839 , apéndice $3^{\circ} \mathrm{al} \mathrm{n}^{\mathrm{o}} 18,18$ de septiembre de 1839, pp. 287-290. DSS. Legislatura de 1840, $\mathrm{n}^{\circ}$ 31, 5 de mayo de 1840, p. 190. Gaceta de Madrid, 20 de noviembre de 1839. DSS. Legislatura de 1839, n ${ }^{\circ}$ 7, 17 de septiembre de 1839, p. 63. El Eco del Comercio, 7 de diciembre de 1839. DSC. Legislatura de 1839, $\mathrm{n}^{\circ}$ 58, 31 de octubre de 1839, pp. 1160-1161. DSC. Legislatura de 1840, $\mathrm{n}^{\circ} 7$, 24 de febrero de 1840, p. 65. TOMÁS VILLARROYA, J. (1990): "Las listas electorales en 1840", en Estudios históricos. Homenaje a los profesores Jover Zamora y Palacio Atard. Madrid. Editorial Complutense, tomo I, pp. 85-100. DSC. Legislatura de 1839, nº 37, 7 de octubre de 1839, p. 697.

3 GÓMEZ APARICIO, P. (1967). Historia del periodismo español. Madrid. Editora Nacional, vol. I, pp. 247-253. FUERTES-ARBOIX, M. (2014). La sátira política en Fray Gerundio (1837-1842) de Modesto Lafuente. Alicante. Publicaciones de la Universidad de Alicante, pp. 72-90. Fray Gerundio, 5 de noviembre de 1839, prospecto. Fray Gerundio, 24 de diciembre de 1839, p. 389.

4 Fray Gerundio, 3 de septiembre de 1839, p. 309. Fray Gerundio, 6 de septiembre de 1839, pp. 312 y 315. Fray Gerundio, 10 de septiembre, p. 328. VARELA SUANZES-CARPEGNA, J. (1984): "La Constitución española de 1837: una Constitución transaccional”, en Revista de Derecho Politico, $\mathrm{n}^{\circ}$ 20, pp. 95-106. ÁLVAREZ BERANGO, L. (2000): "Encuentros en la tercera vía. El problema de la conciliación liberal en el proceso político de 1837 a 1844", en Revista de las Cortes Generales, n 51 , pp. 17-23. Fray Gerundio, 1 de octubre de 1839, pp. 3 y 15. Fray Gerundio, 18 de octubre de 2015, p. 97. Fray Gerundio, 29 de octubre de 1839, pp. 149, 147 y 151. Fray Gerundio, 22 de noviembre de 1839, p. 257. Fray Gerundio, 17 de diciembre de 1839, p. 350. Fray Gerundio, 29 de noviembre de 1839, pp. 294-295. Fray Gerundio, 24 de diciembre de 1839, p. 398. 
5 Fray Gerundio, 31 de diciembre de 1839, p. 434. Fray Gerundio, 17 de enero de 1840, p. 77. Fray Gerundio, 11 de febrero de 1840, pp. 185-186. Fray Gerundio, 21 de febrero de 1840, p. 248. DSC. Legislatura de $1840, \mathrm{n}^{\circ} 6,23$ de febrero de 1840, pp. 49-53. DSC. Legislatura de 1840, $\mathrm{n}^{\circ}$ 7, 24 de febrero de 1840, pp. 72-77. El Correo Nacional, 25 de febrero de 1840. PIRALA, A. (1984): Historia de la guerra civil y de los partidos liberal y carlista. Madrid. Turner/Historia 16, tomo VI, pp. 103-105. Fray Gerundio, 25 de febrero de 1840, pp. 261-262 y 264. Carabanchel era una de las prisiones de Madrid donde Modesto Lafuente estuvo preso en noviembre de 1838 durante cinco días.

6 Fray Gerundio, 28 de febrero de 1840, pp. 267 y 280. Fray Gerundio, 3 de marzo de 1840, pp. 282-285. Fray Gerundio, 6 de marzo de 1840, pp. 301, 303 y 310. DSC. Legislatura de 1840, no 10 , 3 de marzo de 1840, pp. 136-137. DSC. Legislatura de 1840, $\mathrm{n}^{\circ} 11,4$ de marzo de 1840, pp. 154-155. DSC. Legislatura de $1840, \mathrm{n}^{\circ} 12,5$ de marzo de 1840 , pp. 178-179 y 188. DSC. Legislatura de 1840, $\mathrm{n}^{\mathrm{o}} 13,6$ de marzo de 1840 , pp. 196 y 205. DSC. Legislatura de $1840, \mathrm{n}^{\mathrm{o}} 14,7$ de marzo de 1840, pp. 217 y $228-229$. DSC. Legislatura de $1840, \mathrm{n}^{\circ} 15,8$ de marzo de 1840 , pp. $235,245-250$ y $251-252$. DSC. Legislatura de 1840, $\mathrm{n}^{\circ} 16,9$ de marzo de 1840, p. 260. Fray Gerundio, 10 de marzo de 1840, pp. 315-316. FUERTES-ARBOIX, M. (2014): Op. cit., pp. 218-220.

7 Gaceta de Madrid, 13 de marzo de 1840. Fray Gerundio, 20 de marzo de 1840, pp. 332-333 y 360-361. Gaceta de Madrid, 5 de diciembre de 1820. El Eco del Comercio, 21 de marzo de 1840. DSC. Legislatura de 1840, $\mathrm{n}^{\circ}$ 27, 23 de marzo de 1840, p. 612.

8 El Eco del Comercio, 14, 15 y 16 de marzo de 1840. Las mayúsculas en el original. Fray Gerundio, 20 de marzo, pp. 345-350. El Correo Nacional, 15, 16, 17 y 18 de marzo de 1840. El Castellano, 17 de marzo de 1840. El Mensagero, 15 de marzo de 1840. Fray Gerundio, 13 de octubre de 1840, pp. 63-64.

9 MARCUELLO BENEDICTO, J. I. (1986). La práctica parlamentaria en el reinado de Isabel II. Prólogo de Miguel Artola Gallego. Madrid. Congreso de los Diputados, pp. 63-82. DSC. Legislatura de 1840, $\mathrm{n}^{\circ} 27,23$ de marzo de 1840, pp. 611-612, 616 y 618. DSC. Legislatura de 1840, $\mathrm{n}^{\circ} 28,24$ de marzo de 1840, pp. 646 y 640. DSC. Legislatura de 1840, no 31, 27 de marzo de 1840, pp. 719-720. DSC. Legislatura de 1840, $\mathrm{n}^{\circ} 29,25$ de marzo de 1840, pp. 664, 661 y 669. DSC. Legislatura de 1840, $\mathrm{n}^{\mathrm{o}}$ 33, 29 de marzo de 1840, pp. 780-781. Gaceta de Madrid, 28 de febrero de 1822.

10 Fray Gerundio, 20 de marzo de 1840, pp. 351, 350, 354, 357, 361-362, 366, 369-370, 375-376 y 365. Las mayúsculas en el original. Fray Gerundio, 31 de marzo de 1840, p. 418.

11 El Eco del Comercio, 21 de marzo de 1840. Fray Gerundio, 27 de septiembre de 1839, p. 420. LAFUENTE, M. (2002): Historia general de España desde los tiempos más remotos hasta nuestros días: discurso preliminar. Edición de Juan-Sisinio Pérez Garzón. Pamplona. Urgoiti, p. XXI. GÓMEZ APARICIO, P. (1967): Op. cit., pp. 247-253. Fray Gerundio, 20 de marzo de 1840, p. 356. DSC. Legislatura de 1840, $\mathrm{n}^{\mathrm{o}}$ 31, 27 de marzo de 1840, p. 720. El Eco del Comercio, 13 de abril de 1840.

12 El Eco del Comercio, 11 de octubre de 1840. "Joaquín Francisco Pachecho”, en Nicomedes PASTOR DÍAZ y Francisco de CÁRDENAS (1845): Galería de españoles célebres contemporáneos o biografias y retratos de todos los personajes distinguidos de nuestros días en las ciencias, en la política, en las armas, en las letras y en las artes. Madrid. Imprenta y librerías de D. Ignacio Boix, tomo VI, pp. 17-19. Fray Gerundio, 13 de octubre de 1840, pp. 63-65. 